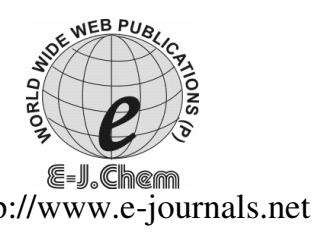

ISSN: 0973-4945; CODEN ECJHAO

E-Journal of Chemistry 2009, 6(S1), S1-S11

\title{
Adsorption of Chromium Ions by Acid Activated Low Cost Carbon-Kinetic,Thermodynamic and Equilibrium Studies
}

\author{
B R.VENKATRAMAN ${ }^{\S *}$, S.PARTHASARATHY ${ }^{\mathbb{I}}$, \\ A.KASTHURI ${ }^{\#}$, P. PANDIAN ${ }^{\S}$ and S ARIVOLI \\ ${ }^{\S}$ P.G \& Research Department of Chemistry, \\ Periyar E.V.R.College (Autonomous), Tiruchirappalli-620 023, Tamilnadu, India. \\ IDepartment of Chemistry, CARE School of Engineering, \\ Tiruchirappalli-620 009, Tamilnadu, India. \\ \#Department of Chemistry, Nehru Memorial College, \\ Puthanampatti, Tiruchirappalli-621 007, Tamilnadu, India. \\ P.G. Department of Chemistry, H.H.The Rajah's College, \\ Pudukkottai- 622 001, Tamilnadu, India. \\ brvenkatrman@yahoo.com
}

Received 10 April 2008; Revised 25 May 2008; Accepted 1 June 2008

\begin{abstract}
A carbonaceous adsorbent prepared from an indigenous waste, by acid treatment was tested for its efficiency in removing metal ions. The process parameters studied include agitation time, initial metal ions concentration, carbon dose, $\mathrm{pH}$ and temperature. The adsorption followed first order reaction equation and the rate is mainly controlled by intra-particle diffusion. Freundlich and Langmuir isotherm models were applied to the equilibrium data. The adsorption capacity $\left(\mathrm{Q}_{\mathrm{m}}\right)$ obtained from the Langmuir isotherm plot were found to around $30 \mathrm{mg} / \mathrm{g}$ at an initial $\mathrm{pH}$ of 7.0. The temperature variation study showed that the metal ions adsorption is endothermic and spontaneous with increased randomness at the solid solution interface. Significant effect on adsorption was observed on varying the $\mathrm{pH}$ of the metal ion solutions. The Langmuir and Freundlich adsorption isotherms obtained, positive $\Delta \mathrm{H}^{0}$ value, $\mathrm{pH}$ dependent results and desorption of metal ions in mineral acid suggest that the adsorption of metal ions on $\mathrm{BBC}$ involves chemisorption as well as physisorption mechanism.
\end{abstract}

Keywords: Activated carbon, Adsorption isotherm, Equilibrium, Thermodynamic parameters.

\section{Introduction}

The problems of the ecosystem are increasing with developing technology. Heavy metal pollution is one of the main problems. Toxic metal compounds coming to the earth's surface not only reach the earth's waters (seas, lakes, ponds and reservoirs) but can also contaminate ground water in trace amounts by leaching from the soil. Therefore, the earth's waters may contain various toxic metals. 
Drinking water is obtained from springs, which may be contaminated, by various toxic metals. Over the past few decades the huge increase in the use of heavy metals has resulted in an increased flux of metallic substances in aquatic environment. The most important characteristics of these metals are that they are toxic to living organisms. One of the most important problems is the accumulation of metals can be more than those in water and air. The contaminated food can cause poisoning in humans and animals ${ }^{1}$. Although some heavy metals are necessary for the growth of plants, after certain concentrations heavy metals become poisonous for both plants and microorganisms. Another important risk concerning contamination is the accumulation of these substances in the soil in the long term. Heavy metals have an effect on the enzymes. It has been determined that various metal ions hinder various enzymes responsible for mineralization of organic compounds in the earth. According to the world health organization, the metals of most immediate concern are chromium, iron, nickel, cadmium, mercury, lead, aluminum, manganese, cobalt, copper and zinc. These metals cause direct toxicity, both to humans and living beings, due to their presence beyond specified limits. Several past disasters are due to the contamination of heavy metals in aquatic environment. Among these are, "minamita tragedy"(Metallic mercury from the laboratories and chlorine manufacturing industries was capable of being converted to concentrated methyl mercury by aquatic life). "Itai-Itai" disease was reported during 1953-1960 due to water containing cadmium form the Jintsu river in Japan $(1947)^{1,2}$.

Metal ion such chromium produces undesirable effects on human and animal life even in low concentrations. In recent years many researchers have studied the removal of different heavy metal ions including chromium, nickel, iron and copper from the water. Wastewaters from industries released in to nearby land or rivers without any treatment because the conventional treatment methods are not cost effective in the Indian context. On the other hand, low cost technologies never allow a wishful metal ion removal and it has certain disadvantages. Adsorption is one of the most effective methods and activated carbon is the preferred adsorbent widely employed to treat wastewater containing different classes of metal ions recognizing the economic drawback of commercial activated carbon. Many investigators have studied the feasibility of using inexpensive alternative materials like pearl millet husk, date pits, saw dust buffing dust of leather industry, coir pith, crude oil residue tropical grass, olive stone and almond shells, pine bark, wool waste, coconut shell etc., as carbonaceous precursors for the removal of metal ion from water and wastewater ${ }^{3,4}$. The present study undertaken to evaluate the efficiency of a carbon adsorbent prepared form acid activated Borassus Bark for the removal of metal ion aqueous solution. In order to design adsorption treatment systems, knowledge of kinetic and mass transfer process is essential. In this paper, we have reported the applicability of kinetic and mass-transfer models for the adsorption of chromium ion onto activated carbon

\section{Experimental}

Carbon was prepared by treating air-dried Borassus bark with con sulphuric acid in a weight ratio of $1: 1$. The resulting black product was kept in a furnace maintained at $500{ }^{\circ} \mathrm{C}$ for 12 hours followed by washing with water until free from excess acid and dried at $150 \pm 5{ }^{\circ} \mathrm{C}$. The carbon product obtained from Borassus bark (BBC) was ground and the portion retained between 30 and $50 \mu \mathrm{m}$ sieves was used in all the experiments. All chemicals supplied by S.d. fine chemicals with high purity.

\section{Batch equilibration method}

All experiments were carried out at $30,40,50$ and $60^{\circ} \mathrm{C}$ temperature in batch mode. Batch mode was selected because of its simplicity and reliability. The experiments were done in different Erlenmeyer glass flasks of $100 \mathrm{~mL}$ capacity. Prior to each experiment, a predetermined amount of 
absorbent was added to each flask. The stirring was kept constant $(120 \mathrm{rpm})$ for each run throughout the experiment to ensure equal mixing. Each flask was filled with a known volume of sample before commencing stirring such as metal solutions with an initial concentration of $5 \mathrm{mg} / \mathrm{L}$ to $30 \mathrm{mg} / \mathrm{L}$. The flask containing the sample was withdrawn from the shaker at the predetermined time interval, filtered and the residual concentration of the metal ion was measured.

\section{Effect of variable parameters}

Dosage of adsorbents

Different doses consisting of 10 to $100 \mathrm{mg} / 50 \mathrm{~mL}$ of the adsorbent is mixed with the metal ion and the mixture was agitated in a mechanical shaker. The percentage of adsorption for different doses was determined by keeping all other factors constant.

\section{Initial concentration}

In order to determine the rate of adsorption, experiments were conducted with different initial concentrations of metal ions ranging from 5 to $30 \mathrm{mg} / \mathrm{L}$. All other factors were kept constant.

\section{Contact time}

The effect of period of contact between the adsorbent and adsorbate on the removal of the metal ions in a single cycle was determined by keeping particle size, initial concentration, dosage, $\mathrm{pH}$, and temperature constant.

\section{Initial $p H$}

Adsorption experiments were carried out at a range of $\mathrm{pH}$ of the solution i.e. 3-9. The acidic and alkaline $\mathrm{pH}$ of the medium was maintained by adding the required amounts of hydrochloric acid and sodium hydroxide solutions. The parameters like particle size of the adsorbents, and temperature were kept constant while carrying out the experiments.

\section{Other ions}

Adsorption studies of a specific metal ion in the presence of calcium and chloride ions were experimentally verified using the adsorbents. This involved the determination of the percentage of metal ion adsorbed from $20 \mathrm{mg} / \mathrm{L}$ of initial concentration of the metal ion solution with varying concentration of the added ion keeping all other factors constant.

\section{Temperature}

The adsorption experiments were performed at four different temperatures viz., 30, 40, 50 and $60{ }^{\circ} \mathrm{C}$ in a thermostated shaker machine (Remi, India). The constancy of the temperature was maintained with an accuracy of $\pm 0.5^{\circ} \mathrm{C}$.

\section{Regeneration studies}

The regeneration of the adsorbed carbon is done by using $0.2 \mathrm{M}$ Mineral acids and sodium chloride solutions.

\section{Results and Discussion}

\section{Effect of contact time and initial metal ion concentration}

The experimental results of adsorptions of Chromium ion on the activated carbon at various concentrations $(5,10,15,20,25$ and $30 \mathrm{mg} / \mathrm{L})$ with contact time are shown in Figure 2 . The equilibrium data were collected in Table 1 reveals that, percent adsorption decreased with increase in initial metal ion concentration, but the actual amount of metal ion adsorbed per unit mass of carbon increased with increase in metal ion concentration. It means that the adsorption is highly dependent on initial concentration of metal ion. It is because of that at lower concentration, the ratio of the initial number of metal ion to the available surface area is low subsequently the 
fractional adsorption becomes independent of initial concentration. However, at high concentration the available sites of adsorption becomes fewer and hence the percentage removal of metal ion is dependent upon initial concentration. Equilibrium have established at 40 minutes for all concentrations. Figure 1 reveals that the curves are single, smooth, and continuous, leading to saturation, suggesting the possible monolayer coverage of the metal ion on the carbon surface 5 .

Table 1. Equilibrium Parameters for the adsorption metal ion onto BBC.

\begin{tabular}{|c|c|c|c|c|c|c|c|c|c|c|c|c|}
\hline \multirow{2}{*}{\multicolumn{2}{|c|}{ Metal ion }} & \multicolumn{7}{|c|}{ Chromium ion adsorption } & \multirow{2}{*}{\multicolumn{4}{|c|}{ Metal ions Removed, \% }} \\
\hline & & \multicolumn{3}{|c|}{$\mathrm{C}_{\mathrm{e}}, \mathrm{mg} / \mathrm{L}$} & \multicolumn{4}{|c|}{$\mathrm{Q}_{\mathrm{e}}, \mathrm{mg} / \mathrm{g}$} & & & & \\
\hline & $30^{\circ}$ & $40^{\circ}$ & $50^{\circ}$ & $60^{\circ}$ & $30^{\circ}$ & $40^{\circ}$ & $50^{\circ}$ & $60^{\circ}$ & $30^{\circ}$ & $40^{\circ}$ & $50^{\circ}$ & $60^{\circ}$ \\
\hline 5 & 0.0925 & 0.0712 & 0.0505 & 0.0250 & 4.9075 & 4.9288 & 4.9435 & 4.9750 & 98.15 & 98.57 & 98.99 & 99.50 \\
\hline 10 & 0.4835 & 0.4052 & 0.3575 & 0.3057 & 9.5165 & 9.5948 & 9.6425 & 9.6 & 95.16 & 95.94 & 96.42 & 96.94 \\
\hline 15 & 1.1550 & 1.0525 & 0.9500 & 0.81 & 13.8450 & 13.9475 & 14.0500 & 14.1 & 92.30 & 92.98 & 93.66 & 94.55 \\
\hline 20 & 1.8750 & 1.7156 & 1.5758 & 1.3955 & 18.1250 & 18.2844 & 18.4242 & 18.6045 & 90.62 & 91.42 & 92.12 & 93.02 \\
\hline 25 & 2.8575 & 2.5500 & 2.2875 & 2.0051 & 22.1425 & 22.4800 & 22.7125 & 22.9949 & 88.57 & 89.80 & 90.85 & 91.97 \\
\hline 30 & 3.9850 & 3.6575 & 3.3016 & 3.0150 & 26.0150 & 26.3425 & 26.6984 & 26.9850 & 86.71 & 87.80 & 88.99 & 89.95 \\
\hline
\end{tabular}

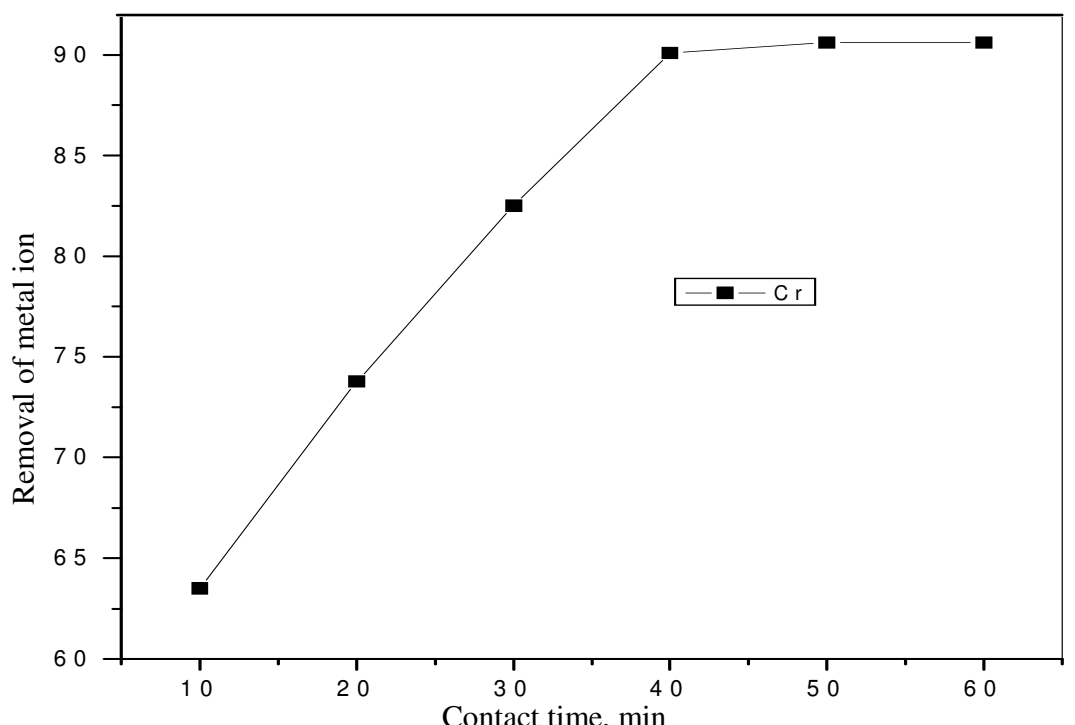

Figure 1. Effect of contact time on the adsorption chromium ion.

\section{Effect of carbon concentration}

The adsorption of the metal ion on carbon was studied by varying the carbon concentration $(10-100 \mathrm{mg} / 50 \mathrm{~mL})$ for Chromium ion concentration of $20 \mathrm{mg} / \mathrm{L}$. The percentage of adsorption increased with increase in the carbon concentration (Figure 1). This has attributed to increased carbon surface area and availability of more adsorption sites ${ }^{6}$.

\section{Adsorption isotherm}

The experimental data analyzed according to the linear form of the Langmuir ${ }^{7}$ and Freundlich ${ }^{8}$ isotherms.

The Langmuir isotherm represented by the following equation

$$
\mathrm{C}_{\mathrm{e}} / \mathrm{Q}_{\mathrm{e}}=1 / \mathrm{Q}_{\mathrm{m}} \mathrm{b}+\mathrm{C}_{\mathrm{e}} / \mathrm{Q}_{\mathrm{m}}
$$

Where $\mathrm{C}_{\mathrm{e}}$ is the equilibrium concentration $(\mathrm{mg} / \mathrm{L}), \mathrm{Q}_{\mathrm{e}}$ is the amount adsorbed at equilibrium ( $\mathrm{mg} / \mathrm{g}$ ) and $\mathrm{Q}_{\mathrm{m}}$ and $\mathrm{b}$ is Langmuir constants related to adsorption efficiency and 
energy of adsorption, respectively. The linear plots of $\mathrm{C}_{e} / \mathrm{Q}_{e}$ versus $\mathrm{C}_{e}$ suggest the applicability of the Langmuir isotherms (Figure 3). Values of $\mathrm{Q}_{\mathrm{m}}$ and $\mathrm{b}$ were determined from slope and intercepts of the plots and are presented in Table 2. From the results, it is clear that the value of adsorption efficiency $Q_{m}$ and adsorption energy $b$ of the carbon increases on increasing the temperature. From the values we can conclude that the maximum adsorption corresponds to a saturated monolayer of adsorbate molecules on adsorbent surface with constant energy and no transmission of adsorbate in the plane of the adsorbent surface.

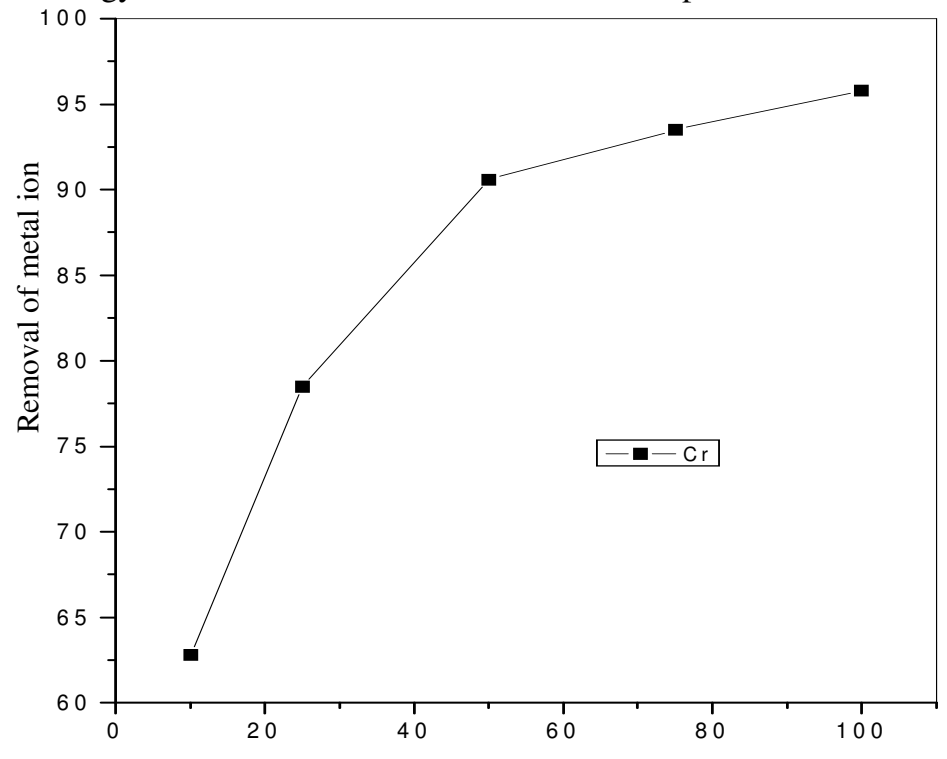

Absorbent dose, mg

Figure 2. Effect of absorbent dose on the adsorption chromium ion.



Figure 3. Langmuir adsorption isotherm for the adsorption of chromium ion. 
Table 2. Langmuir isotherm results.

\begin{tabular}{ccccc}
\hline Metal ion & $\begin{array}{c}\text { Temp } \\
{ }^{\circ} \mathrm{C}\end{array}$ & Statistical parameters & ${ }_{r 2}$ & $\begin{array}{c}\text { Constants } \\
\mathrm{b}\end{array}$ \\
\hline Chromium & 30 & 0.9731 & 30.6484 & 0.9932 \\
ion adsorption & 40 & 0.9711 & 30.4870 & 1.1756 \\
& 50 & 0.9667 & 30.4878 & 1.3633 \\
& 60 & 0.9655 & 30.0661 & 1.7182 \\
\hline
\end{tabular}

Table 3. Freundlich isotherm results.

\begin{tabular}{ccccc}
\hline Metal ion & $\begin{array}{c}\text { Temp } \\
{ }^{\circ} \mathrm{C}\end{array}$ & $\begin{array}{c}\text { Statistical parameters } \\
r^{2}\end{array}$ & $\mathrm{k}_{\mathrm{f}}$ & $\begin{array}{c}\text { Constants } \\
\mathrm{n}\end{array}$ \\
\hline Chromium & 30 & 0.9851 & 1.7627 & 1.7639 \\
ion adsorption & 40 & 0.9985 & 1.7765 & 1.7400 \\
& 50 & 0.9770 & 1.8190 & 1.6714 \\
& 60 & 0.9962 & 1.9859 & 1.5379 \\
\hline
\end{tabular}

The trend shows that the adsorbent prefers to bind acidic ions and that speciation predominates on sorbent characteristics, when ion exchange is the predominant mechanism. Further, it confirms the endothermic nature of the processes involved in the system ${ }^{9}$. To confirm the adorability of the adsorption process, the separation factor $\left(\mathrm{R}_{\mathrm{L}}\right)$ has calculated and presented in Table 4 . The values were found to be between 0 and 1 and confirm that the ongoing adsorption process is favourable ${ }^{10}$

Table 4. Dimensionless separation factor $\left(\mathrm{R}_{\mathrm{L}}\right)$.

\begin{tabular}{ccccc}
\hline Chromium ion, mg/L & \multicolumn{4}{c}{ Temperature, ${ }^{\circ} \mathrm{C}$} \\
\cline { 2 - 5 } & $30^{\circ}$ & $40^{\circ}$ & $50^{\circ}$ & $60^{\circ}$ \\
\hline 5 & 0.168 & 0.145 & 0.128 & 0.104 \\
10 & 0.091 & 0.078 & 0.068 & 0.055 \\
15 & 0.063 & 0.054 & 0.047 & 0.037 \\
20 & 0.048 & 0.041 & 0.035 & 0.028 \\
25 & 0.039 & 0.033 & 0.029 & 0.022 \\
30 & 0.032 & 0.028 & 0.024 & 0.019 \\
\hline
\end{tabular}

The Freundlich equation have also employed for the adsorption of Chromium ion on the adsorbent. The Freundlich isotherm have represented as

$$
\log \mathrm{Q}_{\mathrm{e}}=\log \mathrm{K}_{\mathrm{f}}+1 / \mathrm{n} \log \mathrm{C}_{\mathrm{e}}
$$

Where $\mathrm{Q}_{\mathrm{e}}$ is the amount of Chromium ion adsorbed (mg/g), $\mathrm{C}_{\mathrm{e}}$ is the equilibrium concentration of metal ion in solution $(\mathrm{mg} / \mathrm{L})$ and $\mathrm{K}_{\mathrm{f}}$ and $\mathrm{n}$ are constants incorporating all factors affecting the adsorption capacity and intensity of adsorption, respectively. Linear plot of $\log \mathrm{Q}_{\mathrm{e}}$ versus $\log \mathrm{C}_{\mathrm{e}}$ shows that the adsorption of chromium ion follows the Freundlich isotherm (Figure 4). Values of $\mathrm{K}_{\mathrm{f}}$ and $\mathrm{n}$ were found and given in the Table 3, shows the increase of negative charge on the surface that enhances the electrostatic force like Van der Waal's between the carbon surface and metal ion, which increases the adsorption of Chromium ion. The values clearly show that dominance in adsorption capacity. The intensity of adsorption is an indicative of the bond energies between metal ion and adsorbent and the possibility of slight chemisorptions rather than physisorption. The possibility of multilayer adsorption of metal ion through the percolation process cannot be ruled out. However, the values of $n$ is greater than one indicating the adsorption is much more favourable 11,5 


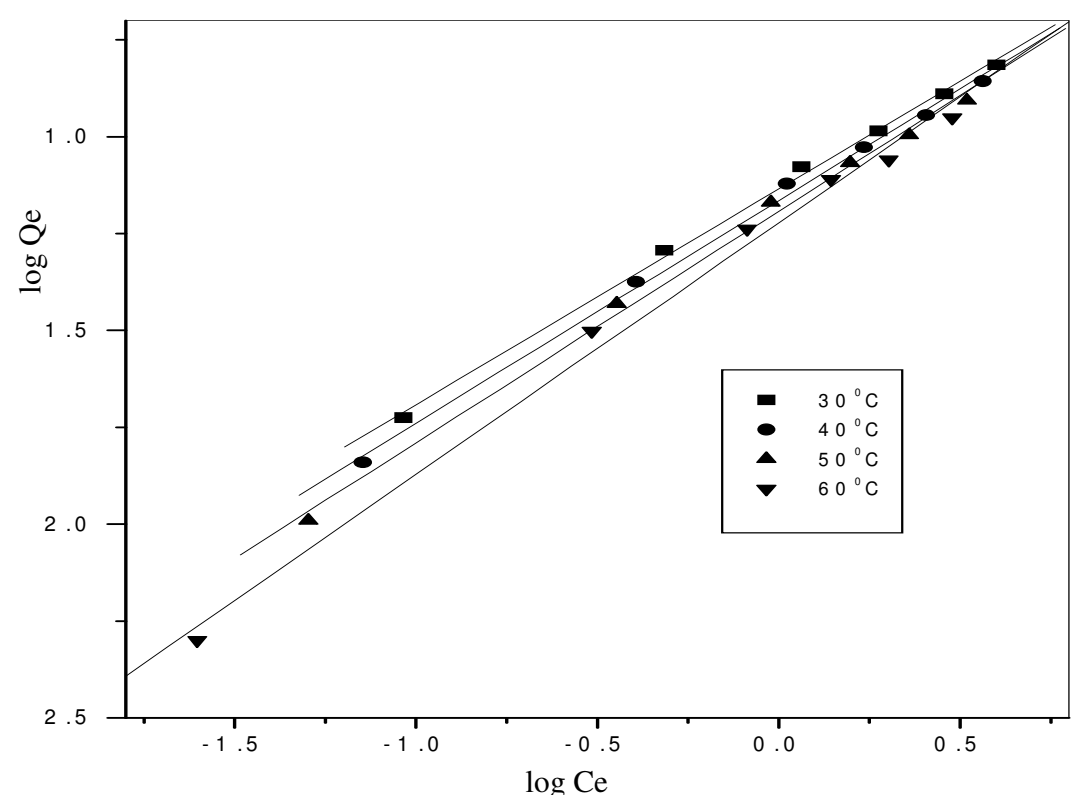

Figure 4. Freundich adsorption isotherms for the adsorption of chromium ion.

\section{Kinetics of adsorption}

Kinetics of sorption describes the solute uptake rate, which in turn governs the residence time of sorption reaction. It is one of the important characteristics in defining the efficiency of sorption. In the present study, the kinetics of the metal ion removal has carried out to understand the behaviour of this low cost carbon adsorbent. The adsorption of metal ions from an aqueous solution follows reversible first order kinetics, when a single species considered on a heterogeneous surface. The heterogeneous equilibrium between the metal ion solution and the activated carbon have expressed as:

$$
\mathrm{A} \underset{\mathrm{k}_{2}}{\stackrel{\mathrm{k}_{1}}{\gtrless}} \mathrm{B}
$$

Where $\mathrm{k}_{1}$ is the forward rate constant and $\mathrm{k}_{2}$ is the backward rate constant. A represents metal ion remaining in the aqueous solution and $\mathrm{B}$ represents metal ion adsorbed on the surface of activated carbon. The rate constants calculated as earlier. The data furnished in Table 6, is evident that the forward rate constant is much higher than the backward rate constant suggesting that the rate of adsorption is clearly dominant. At equilibrium, the rate is the ratio of the concentration of adsorbate in adsorbent and concentration of adsorbate in aqueous solution given by $\mathrm{K}_{0}$. The calculated values presented in the Table 5 . The result indicates that $\mathrm{K}_{0}$ values decreases with increase in the concentration of the metal ion and increases with increase in temperature.

A clear examination of the effect of metal ion concentrations on the rate constant $\mathrm{K}_{\mathrm{ad}}$ (Table 6), the values help to describe the mechanism of metal ion removal taking place ${ }^{5}$.In cases of strict surface adsorption a variation of rate should be proportional to the first power of concentration. However, when pore diffusion limits the adsorption process, the relationship between initial metal ion concentration and rate of reaction will not be linear. It shows that pore diffusion limits the overall rate of metal ion adsorption ${ }^{12,13}$. 
Table 5. Equilibrium constant and thermodynamic parameters for the adsorption of metal ions onto acid activated carbon.

\begin{tabular}{|c|c|c|c|c|c|c|c|c|c|c|}
\hline \multirow{3}{*}{$\begin{array}{l}\text { Chromium } \\
\text { ion }(\mathrm{mg} / \mathrm{L})\end{array}$} & \multicolumn{8}{|c|}{ Temperature, ${ }^{\circ} \mathrm{C}$} & \multirow{3}{*}{$\Delta \mathrm{H}^{\circ}$} & \multirow{3}{*}{$\Delta \mathrm{S}^{\circ}$} \\
\hline & \multicolumn{4}{|c|}{$\mathrm{K}_{\mathrm{o}}$} & \multicolumn{4}{|c|}{$-\Delta G^{\circ}$} & & \\
\hline & $30^{\circ}$ & $40^{\circ}$ & $50^{\circ}$ & $60^{\circ}$ & $30^{\circ}$ & $40^{\circ}$ & $50^{\circ}$ & $60^{\circ}$ & & \\
\hline 5 & 9.21 & 10.03 & 11.09 & 11.63 & 10.00 & 11.02 & 12.31 & 14.65 & 35.43 & 149.01 \\
\hline 10 & 9.80 & 10.07 & 10.30 & 10.82 & 7.50 & 8.23 & 8.84 & 9.56 & 12.92 & 67.46 \\
\hline 15 & 6.78 & 7.60 & 8.36 & 9.54 & 6.25 & 6.72 & 7.23 & 7.89 & 10.02 & 53.59 \\
\hline 20 & 5.35 & 5.63 & 6.03 & 6.64 & 5.71 & 6.15 & 6.59 & 7.16 & 17.23 & 75.35 \\
\hline 25 & 3.21 & 3.35 & 3.53 & 3.63 & 5.15 & 5.65 & 6.16 & 6.75 & 10.75 & 52.42 \\
\hline 30 & 2.82 & 2.97 & 3.08 & 3.17 & 4.72 & 5.13 & 5.61 & 6.06 & 8.84 & 44.69 \\
\hline
\end{tabular}

The contact-time experimental results can be used to study the rate-limiting step in the adsorption process, as shown by Weber and Morris ${ }^{14}$. Since the particles are vigorously agitated during the adsorption period, it is probably reasonable to assume that the rate is not limited by mass transfer from the bulk liquid to the particle external surface, one might then postulate that the rate-limiting step may be either film or intra-particle diffusion. As they act in series, the slower of the two will be the rate-determining step.

Table 6. Rate constants for the adsorption of metal ions $\left(10^{3} \mathrm{k}_{\mathrm{ad}}, \mathrm{min}^{-1}\right)$ and the constants for forward $\left(10^{3} \mathrm{~K}_{1}, \mathrm{~min}^{-1}\right)$ and reverse $\left(10^{3} \mathrm{~K}_{2}, \mathrm{~min}^{-1}\right)$ process.

\begin{tabular}{|c|c|c|c|c|c|c|c|c|c|c|c|c|}
\hline \multirow{3}{*}{$\begin{array}{l}\text { Chrom- } \\
\text { ium ion, } \\
\mathrm{mg} / \mathrm{L}\end{array}$} & \multicolumn{12}{|c|}{ Temperature, ${ }^{\circ} \mathrm{C}$} \\
\hline & \multicolumn{4}{|c|}{$\mathrm{k}_{\mathrm{ad}}$} & \multirow{2}{*}{\multicolumn{2}{|c|}{$\frac{\mathrm{k}_{1} \mathrm{k}_{2}}{30^{\circ}}$}} & $\mathrm{k}_{1}$ & $\mathrm{k}_{2}$ & $\mathrm{k}_{1}$ & $\mathrm{k}_{2}$ & $\mathrm{k}_{1}$ & $\mathrm{k}_{2}$ \\
\hline & $30^{\circ}$ & $40^{\circ}$ & $50^{\circ}$ & $60^{\circ}$ & & & \multicolumn{2}{|c|}{$40^{\circ}$} & \multicolumn{2}{|c|}{$50^{\circ}$} & \multicolumn{2}{|c|}{$60^{\circ}$} \\
\hline 5 & 5.32 & 26.57 & 18.97 & 38.69 & 5.22 & 0.10 & 26.22 & 0.38 & 18.77 & 0.19 & 38.49 & 0.19 \\
\hline 10 & 30.94 & 34.60 & 37.37 & 40.82 & 29.45 & 1.49 & 33.20 & 1.40 & 36.04 & 3 & 39. & 1.24 \\
\hline 15 & 12.00 & 17.80 & 19.45 & 21.55 & 11.08 & 0.92 & 16.56 & 1.24 & 18.22 & 1.23 & 20. & 1.17 \\
\hline 20 & 11.22 & 12.11 & 12.61 & 14.55 & 10.17 & 1.05 & 11.08 & 1.03 & 11.62 & 0.99 & 13.54 & 1.01 \\
\hline 25 & 7.77 & 8.55 & 9.46 & 10.62 & 6.89 & 0.88 & 7.68 & 0.87 & 8.59 & 0.86 & 9.77 & 0.85 \\
\hline 30 & 5.75 & 6.22 & 6.80 & 7.46 & 4.49 & 1.25 & 5.47 & 0.75 & 6.05 & 0.75 & 6.72 & 0.74 \\
\hline
\end{tabular}

The rate constant for intra-particle diffusion is obtained using the equation

$$
\mathrm{Q}=\mathrm{K}_{\mathrm{p}} \mathrm{t}^{1 / 2}+\mathrm{C}
$$

Here, $K_{p}(\mathrm{mg} / \mathrm{g} / \mathrm{min})$ is the intra-particle diffusion rate constant. The $\mathrm{K}_{\mathrm{p}}$ values obtained from the slope of the linear portions of the curves at each metal ion concentration (Table 7). The $\mathrm{K}_{\mathrm{p}}$ values increased with increase in the metal ion concentration, which reveals that the rate of adsorption is governed by the diffusion of adsorbed metal ion within the pores of the adsorbent ${ }^{15}$.

Table 7. Intra-particle diffusion $\left(\mathrm{K}_{\mathrm{p}}\right)$

\begin{tabular}{cc}
\hline [Chromium ion] $\mathrm{mg} / \mathrm{L}$ & $\mathrm{K}_{\mathrm{p}}$ \\
\cline { 2 - 3 } 5 & 0.036 \\
10 & 0.258 \\
15 & 0.249 \\
20 & 0.224 \\
25 & 0.226 \\
30 & 0.245 \\
\hline
\end{tabular}

\section{Effect of temperature}

The adsorption capacity of the carbon increased with increase in the temperature of the system from $30^{\circ}-60^{\circ} \mathrm{C}$. Thermodynamic parameters such as change in free energy $\left(\Delta \mathrm{G}^{\circ}\right)$, 
enthalpy $\left(\Delta \mathrm{H}^{\circ}\right)$ and entropy $\left(\Delta \mathrm{S}^{\circ}\right)$ were determined using the following equations ${ }^{16,17}$

$$
\begin{aligned}
\mathrm{K}_{0} & =\mathrm{C}_{\text {solid }} / \mathrm{C}_{\text {liquid }} \\
\Delta \mathrm{G}^{\circ} & =-\mathrm{RT} \ln \mathrm{K}_{\mathrm{O}} \\
\operatorname{Iog} \mathrm{K}_{0} & =\Delta \mathrm{S}^{\circ} /(2.303 \mathrm{RT})-\Delta \mathrm{H}^{\circ} /(2.303 \mathrm{RT})
\end{aligned}
$$

Where Ko is the equilibrium constant, $\mathrm{C}_{\text {solid }}$ is the solid phase concentration at equilibrium $(\mathrm{mg} / \mathrm{L}), \mathrm{C}_{\text {liquid }}$ is the liquid phase concentration at equilibrium $(\mathrm{mg} / \mathrm{L}), \mathrm{T}$ is the temperature in Kelvin and $\mathrm{R}$ is the gas constant. The $\Delta \mathrm{H}^{\circ}$ and $\Delta \mathrm{S}^{\circ}$ values obtained from the slope and intercept of Van't Hoff plots have presented in Table 5. The values are with in the range of 1 to $93 \mathrm{~kJ} / \mathrm{mol}$ indicates the favourability of physisorption. From the order we could make out physisorption is much more favourable for chromium ion. The positive values of $\Delta \mathrm{H}^{\circ}$ show the endothermic nature of adsorption and it governs the possibility of physical adsorption. Because in the case of physical adsorption, while increasing the temperature of the system, the extent of metal ion adsorption increases, this rules out the possibility of chemisorptions. However, the very low $\Delta \mathrm{H}^{\circ}$ value depicts metal ion is physisorbed onto adsorbent ${ }^{9,18}$

The negative values of $\Delta \mathrm{G}^{\circ}$ (Table 5) shows the adsorption is highly favourable for Chromium ion. However, it indicates that the metal ion adsorption was spontaneous. The positive values of $\Delta \mathrm{S}^{\circ}$ (Table 5) shows the increased disorder and randomness at the solid solution interface of with adsorbent BBC. While the adsorption there are some structural changes in the metal ion and the adsorbent occur. The adsorbed water molecules, which have displaced by the adsorbate species, gain more translational entropy than is lost by the adsorbate molecules, thus allowing the prevalence of randomness in the system ${ }^{5,12,18}$. From the results, we could make out that more efficient physisorption. Enhancement of adsorption capacity of the activated carbon at higher temperatures has attributed to the enlargement of pore size and activation of the adsorbent surface ${ }^{11}$.

\section{Effect of $p H$}

The experiments carried out at different $\mathrm{pH}$ shows that there was a change in the percent removal of metal ion over the entire $\mathrm{pH}$ range of 3 to 9 shown in the Figure 5, This indicates the strong force of interaction between the metal ion and the activated carbon that, either $\mathrm{H}^{+}$or $\mathrm{OH}^{-}$ions could influence the adsorption capacity. Here the interaction is more at $\mathrm{pH} 6$, the competence of acidic $\mathrm{H}^{+}$ion with metal cation for the sorption sites. The percentage of sorption increased at the above $\mathrm{pH}$ value is due to the presence of ionic $\mathrm{COOH}$ groups. The adsorption of metal ion on the activated carbon does involve ion exchange mechanism. Due to the adsorption of metal ion through ion exchange mechanism by the adsorbent, there should be an influence on the metal ion adsorption while varying the $\mathrm{pH}$. This observation is in line with the type I isotherm shown in Figure $3 \& 4$. The positive $\Delta \mathrm{H}^{\circ}$ value obtained, which indicates irreversible adsorption probably due to polar interaction ${ }^{10,11,19}$.

\section{Desorption studies}

Desorption studies help to elucidate the nature of adsorption and recycling of the spent adsorbent and the metal ion. If the adsorbed metal ion can be desorbed using neutral $\mathrm{pH}$ water, then the attachment of the metal ion of the adsorbent is by weak bonds. If sulphuric acid or alkaline water desorp the metal ion, then the adsorption is by ion exchange. If organic acids, like acetic acid can desorp the metal ion, then the metal ion has held by the adsorbent through chemisorption ${ }^{19}$. The effect of various reagents used for desorption studies indicate that hydrochloric acid is a better reagent for desorption, because we could get more than $90 \%$ removal of adsorbed metal ion. The reversibility of adsorbed metal ion in mineral acid or base is in agreement with the $\mathrm{pH}$ dependent results obtained. The desorption of metal ion by mineral acids and alkaline medium indicates that the metal ion was adsorbed onto the activated carbon through by physisorption mechanisms. 




\section{Effect of other ions}

Figure 5. Effect of $\mathrm{pH}$ on the removal of chromium ion.

The effect of other ions like $\mathrm{Ca}^{2+}$ and $\mathrm{Cl}^{-}$on the adsorption process studied at different concentrations. The ions added to $20 \mathrm{mg} / \mathrm{L}$ of metal ion solutions and the contents were agitated for $60 \mathrm{~min}$ at $30^{\circ} \mathrm{C}$. The results had shown in the Figure 6 reveals that low concentration of $\mathrm{Cl}^{-}$ does not affect the percentage of adsorption of metal ion on activated carbon, because the interaction of $\mathrm{Cl}^{-}$at available sites of adsorbent through competitive adsorption is not so effective. While the concentration of other ion $\mathrm{Ca}^{2+}$ increases, the interference of these ions at available surface sites of the sorbent through competitive adsorption increases that, decreases the percentage adsorption. The interference was more in the presence of $\mathrm{Ca}^{2+}$ compared with $\mathrm{Cl}^{-}$ion. This is so because ions with smaller hydrated radii decrease the swelling pressure with in the sorbent and increase the affinity of the sorbent for such ions ${ }^{12,17,19}$



Figure 6. Effect of other ions on the adsorption of chromium ion. 


\section{Conclusions}

The experimental data correlated reasonably well by the Langmuir and Freundlich adsorption isotherms and the isotherm parameters were calculated. The amount of chromium ion adsorbed increased with increase in $\mathrm{pH}$ of the medium. The amount of chromium ion adsorbed slightly decreased with increasing ionic strength and increased with increase in temperature. The dimensionless separation factor $\left(\mathrm{R}_{\mathrm{L}}\right)$ showed that the activated carbon could be used for the removal of chromium ion from aqueous solution. The values of $\Delta \mathrm{H}^{\circ}$, $\Delta \mathrm{S}^{\circ}$ and $\Delta \mathrm{G}^{\circ}$ results shows that the carbon employed has a considerable potential as an adsorbent for the removal of chromium ion.

\section{References}

1. Hodgate M W, A Perspective of Environmental Pollution; Cambridge University Press, Cambridge, 1979.

2. Vladimir Novotny P E and Gordon Chesters, Handbook of Non-point Pollution: Sources and Management; Van Nostrand Reinhold Company, New York, 1991.

3. Selvarani K, Studies on Low cost Adsorbents for the removal of Organic and Inorganics from Water, Ph D., Thesis, Regional Engineering College, Tiruchirapalli, India, 2000.

4. Sekaran G, Shanmugasundaram K A, Mariappan M and Raghavan K V, Indian J Chem Technol., 1995, 2, 311.

5. Namasivayam C and Yamuna R T, Environ Pollut., 1995, 89, 1.

6. Namasivayam C, Muniasamy N, Gayatri K, Rani M and Ranganathan K, Biores Technol., 1999, 57, 37.

7. Langmuir I, J Am Chem Soc., 1918, 40, 1361.

8. Freundlich H, Phys Chemie., 1906, 57, 384.

9. Senthikumar S, Varatharajan P R, Porkodi K and Subburaam C V, J Colloid Interf Sci., 2005, 284, 79.

10. Krishna D G and Bhattacharyyya G, Appl Clay Sci., 2002, 20, 295.

11. Vadivelan V and Vasanthkumar K, J Colloid Interf Sci., 2005, 286, 91.

12. Rengaraj S, Sivabalan R, Banumathi Arabindoo and Murugesan V, Indian J Chem Technol., 2000, 7, 129.

13. Rengaraj S, Banumathi Arabindoo and Murugesan V, Indian J Chem Technol., 1999, 6, 1.

14. Weber W J and Morris J C, J San Eng Div. ASCE, 1963, 89, 31 .

15. Weber W J, Principle and Application of Water Chemistry, Edited by Faust S D and Hunter J V Wiley, New York, 1967.

16. Khattri S D and Singh M K, Indian J Chem Technol., 1999, 3, 114.

17. Sivaraj R, Namasivayam C and Kadirvelu K, Waste Management, 2001, 21, 105.

18. Renmin Gong, Yingzhi Sun, Jian Chen, Huijun Liu and Chao yang, Dyes and Pigments, 2005, 67, 179.

19. Anuirudhan T S and Sreedhar M K, Indian J Environ Protect., 1999, 19, 8. 


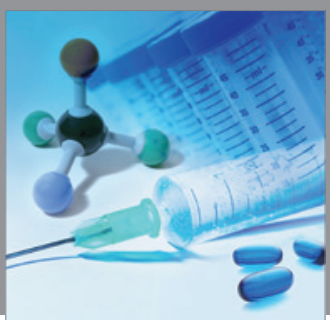

International Journal of

Medicinal Chemistry



Carbohydrate Chemistry

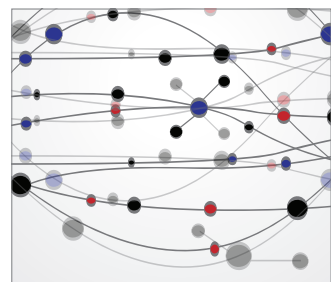

The Scientific World Journal

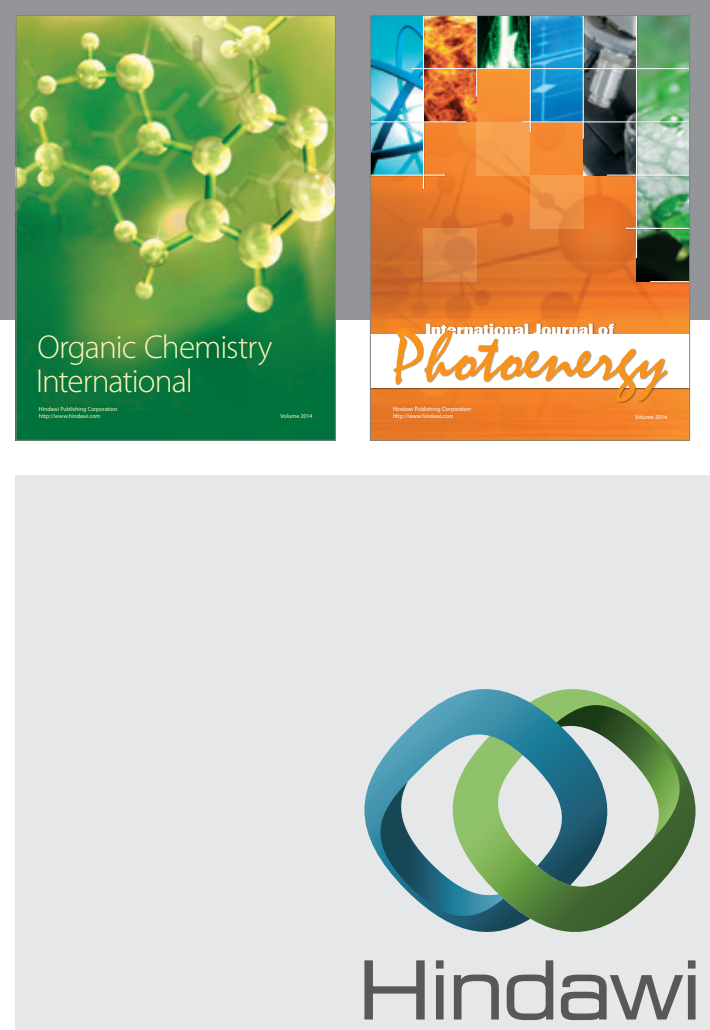

Submit your manuscripts at

http://www.hindawi.com
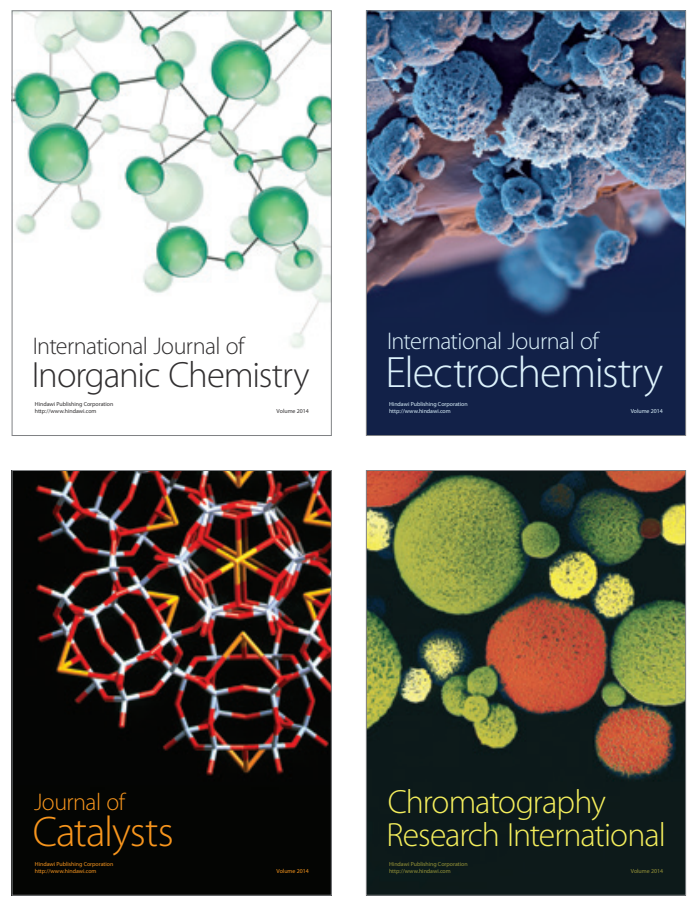
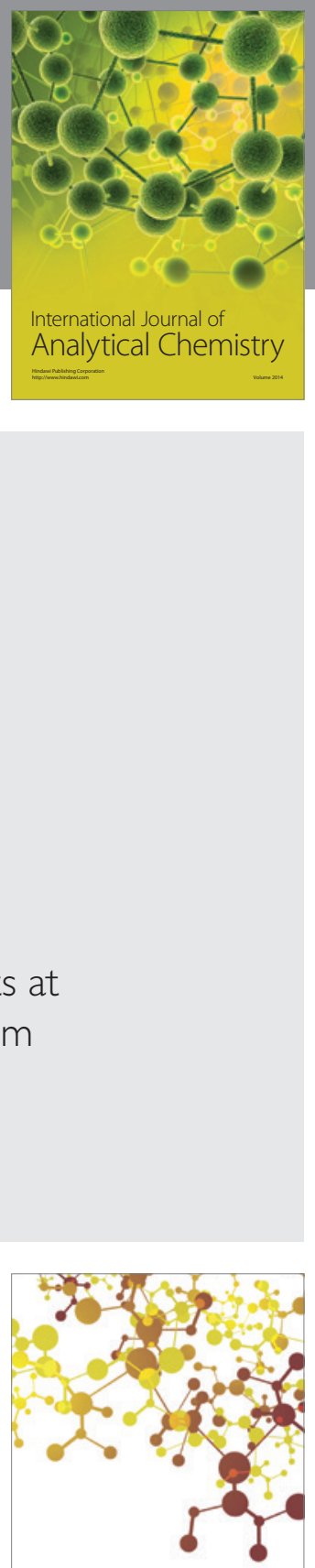

Journal of

Applied Chemistry
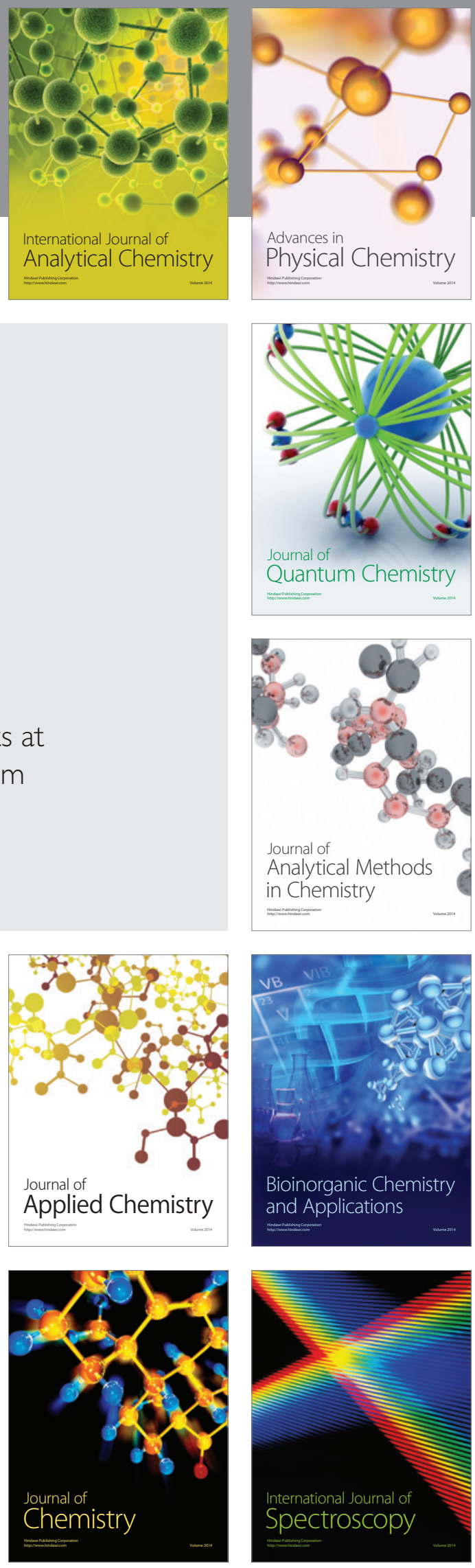